\title{
Viviendas ubicadas en áreas de riesgo de incendios forestales de interfaz. Un análisis territorial y normativo desde Chile
}

\author{
Rose Marie Garay Moena ${ }^{1}$ | Miguel Castillo Soto ${ }^{2}$ | Ricardo Tapia Zarricueta ${ }^{3}$
}

Recibido: 07-01-2020 | en su versión final: 09-02-2021

Resumen

\begin{abstract}
Dada la frecuencia e intensidad de los eventos climáticos, es esencial conectar los instrumentos de planificación y gestión de riesgo territorial con exigencias a construcciones ubicadas en zonas de riesgos. Si se inspeccionan preventivamente edificaciones de áreas rurales y periurbanas con bajas especificaciones técnicas de seguridad contra incendios de interfaz forestal, es posible planificar medidas preventivas con la debida antelación, bajo estándares legalmente aplicables. La experiencia internacional señala que las viviendas pueden ser más seguras, por ejemplo, estableciendo áreas de protección (30-60 metros) y actuando sobre la densidad y distanciamiento de la vegetación combustible. En este sentido, este estudio aborda la protección considerando la relación del entorno inmediato con las características de la edificación bajo amenaza. Para este propósito se revisan las regulaciones chilenas, estadounidenses, europeas y australianas con respecto a la garantía de rendimiento frente a incendios de edificios y su entorno inmediato, extrayendo estándares de calidad y recomendaciones, considerando las necesidades y regulaciones "casa hacia adentro" y "casa hacia afuera". Medidas de seguridad específicas como resistencia al fuego de elementos estructurales y no estructurales, materialidad incombustible, no inflamabilidad, no toxicidad y opacidad de humos; aumento de masividad y cobertura con elementos incombustibles; limitaciones de uso de materiales plásticos y otros que aporten carga combustible, son aspectos de protección pasiva a ser incluidos en evaluación preventiva de edificaciones que conduzcan a recomendaciones y mejoras para disminuir la vulnerabilidad.
\end{abstract}

Palabras clave: Protección pasiva construcciones madera; Interfaz de incendios forestales; resistencia al fuego; normas constructivas

Citación

Garay Moena, R. et al. (2021). Viviendas ubicadas en áreas de riesgo de incendios forestales de interfaz. Un análisis territorial y normativo desde Chile. ACE: Architecture, City and Environment, 16(46), 9523. DOI: http://dx.doi.org/10.5821/ace.16.46.9523

\section{Housing Located at WUI Areas, Under Wildfire Risk Hazard. A Territorial and Normative Analysis from Chile}

Abstract

\begin{abstract}
Given the frequency and intensity of climatic events, it is essential to connect the territorial risk planning and management instruments with requirements to buildings located in risk areas. If buildings in rural and periurban areas with low technical specifications at wildland urban interface, fire safety are pre-emptively inspected, it is possible to plan preventive measures, under legally applicable standards. International experience indicates that houses can be safer, for example, establishing protection areas (30-60 meters) and acting on the density and spacing of combustible vegetation. In this sense, this study addresses protection considering the relationship of the immediate environment with the characteristics of the building under threat. For this purpose, the Chilean, American, European and Australian regulations are reviewed with respect to the guarantee of fire performance of buildings and their immediate environment, extracting quality standards and recommendations, considering the needs and regulations house in and house out. . Specific security measures such as fire resistance of structural and non-structural elements, non-combustible material, non-flammability, non-toxicity and opacity of fumes; increased massiveness and coverage with noncombustible elements; limitations of use of plastic materials and others that provide fuel load are passive protection aspects to be included in evaluation.
\end{abstract}

Keywords: Wood buildings safety; wildland urban interface; wood fire resistant; standard building

\footnotetext{
1 Magister en Ciencias e Industrias de la madera, Universidad de Chile (ORCiD: 0000-0002-7662-9724, ResearcherID: AAR-6185-2021), ${ }^{2}$ Doctor en Recursos Naturales y Sostenibilidad. Universidad de Chile (ORCiD: 0000-0002-3880-9441; ResearcherID: I-4639-2014), ${ }^{3}$ Doctor en Arquitectura, Universidad de Chile (ORCID: 00000003-1790-7744; ResearcherID: J-5089-2016). Correo de contacto: rgaray@uchile.cl
} 


\section{Introducción}

La interfaz urbano-forestal, ocurre, entre otros acontecimientos, cuando viviendas u otras edificaciones, coexisten en el mismo espacio que el arbolado y matorrales, por tanto, hay una fricción entre aquellas y la vegetación (Castillo et al., 2020; CFA 2012, AUSTRALIAN STANDARD®. AS3959, 2009). Estas edificaciones, por sus características estructurales y volumen de material inflamable, aportan sustantivamente a la carga de combustible proveniente de la vegetación, promoviendo de esta manera una combinación que favorece la complejidad en el comportamiento del fuego. En efecto, a mayor número y densidad de viviendas existirá mayor propensión a la propagación del fuego.

Si las edificaciones estuviesen bien planificadas, organizadas y gestionadas, teniendo en cuenta las variadas características geográficas y climáticas, se multiplicarían las infraestructuras sólidas, pudiendo mantenerse firmes en caso de variados desastres naturales (Garay et al., 2020; Dombeck et al., 2004). En Chile, se suele afirmar que los edificios pasan estrictas normas constructivas, basadas en cálculos estructurales (Barrientos, 2016; Barahona, 2020), pero se requiere comprender estos alcances para las viviendas, más aún si estas son prefabricadas en madera, con ampliaciones usualmente irregulares, de diversa materialidad y exposición al fuego.

Los desastres naturales, como los incendios forestales, representan una amenaza catastrófica para el mundo (Ojeda et al., 2019; Garay et al., 2019d).

Así lo han entendido muchos países, que aun disponiendo de normas actualizadas y los recursos necesarios para su gestión, presentan igualmente severos problemas derivados de la expansión de los incendios hacia áreas habitadas. En Australia, por ejemplo, la simulación es una de las herramientas que ha aportado a anticiparse a la ocurrencia de incendios forestales, en tal sentido los hallazgos de Halgamuge et al., (2020) sugieren que el nuevo optimizador Adagrad, proporciona menos tiempo de predicción, así como mejor comprensión de la búsqueda de los lugares donde se inicia el incendio y que tienen más probabilidades de ocurrir, ambos factores, críticos para los incendios forestales de rápida propagación. En Chile, la simulación, logra identificar grandes áreas propensas a incendios (CONAF, 2020), tal como se sabía con cierta antelación que probablemente la localidad denominada Santa Olga en la comuna de Constitución se quemaría en un gran incendio forestal en el 2017 (Galilea, 2019). Así como el impacto del cambio de uso de suelos en la probabilidad de incendios y otros desastres (Ortega, 2019; Ramírez, 2019).

El ordenamiento territorial y sus instrumentos, no han estado, precisamente, diseñados para responder a este tipo de riesgos y su magnitud, al menos en Chile. O bien, son limitados, atrasados y lentos en su operatividad, lo que los hace ir detrás de los efectos e impactos producidos por estas y otras amenazas (Romero Aloy, 2019). Ello, por ende, se replica en una gobernanza que adolece de estos mismos problemas (Rinaldi y Bergamini, 2020).

En efecto, pues mientras el territorio cambia constantemente su conformación, las normas técnicas sobre edificaciones no van en concordancia con la celeridad de estos cambios. A modo de ejemplo, en Chile, la normativa de resistencia al fuego está descrita en la Ordenanza General de Urbanismo y Construcción, OGUC, (Ministerio de Vivienda y Urbanismo, 2009), bajo la hipótesis de que "el fuego se produce en el interior de las viviendas", lo que establece a priori, una inclinación a la gestión preventiva "vivienda hacia adentro", pero aún no asociada al entorno (vivienda hacia afuera). Se suma a ello, el que las condiciones exteriores se encuentran escasamente reguladas, siendo la Corporación Nacional Forestal, CONAF de Chile, la institución encargada de entregar prescripciones a los habitantes en la interfaz (CONAF 2015). La alta acumulación de material vegetal combustible, junto al efecto del cambio climático, entre los principales factores, han hecho que, especialmente en climas de tipo mediterráneo, se ocasionen nuevos y devastadores incendios que se inician en zonas arboladas y

ACE, 16 (4.6) CC BY-ND 3.0 ES | UPC Barcelona, España | Viviendas ubicadas en áreas de riesgo de incendios

forestales de interfaz. Un análisis territorial y normativo desde Chile. DOI: http://dx.doi.org/10.5821/ace.16.46.9523 
luego se propagan hacia áreas pobladas. Los graves eventos en Chile en el 2017, España, Italia, California, Portugal, Marruecos y Grecia en el 2018, muestran esta realidad.

Los incendios forestales varían en función de variables y factores que inciden en el comportamiento del fuego (Galilea, 2019; Generalitat Valenciana, 2014). Las variables corresponden, esencialmente, al monto de energía liberada del proceso de ignición y posterior combustión, de la altura y actividad de las llamas, del calor radiactivo en diferentes ejes de propagación y la velocidad de avance del fuego tanto en la vegetación como en los materiales afectados por efecto de la radiación y la convección. Los factores corresponden al ambiente por el cual se propaga el fuego: la pendiente del terreno, el efecto del viento (velocidad, dirección y duración), y factores meteorológicos locales tales como temperatura, la humedad relativa del aire y el contenido de humedad de los materiales. La carga de combustible disponible y su continuidad, y también la configuración (densidad y distribución), influyen esencialmente en la permanencia y velocidad de propagación de las llamas (Castillo et al, 2016; Peters et al. 2013). Con todos estos aspectos, entonces, tales incendios pueden adquirir distintas tipologías. Los hay de tipo superficial de rápida propagación, cuando existe un alto abastecimiento de oxígeno y carga moderada de combustible; en grado opuesto están los incendios con alta actividad convectiva, atribuible al microclima que se genera por el comportamiento extremo de las llamas, situación muy común cuando el fuego quema de manera progresiva construcciones inflamables. En aquellos casos, las prescripciones previas sobre materialidad y normas de construcción condicionan fuertemente la oportunidad de respuesta frente al control, de manera de evitar la propagación hacia infraestructuras vecinas. (Herrero et al., 2012, Groot et al., 2012, Garay et al., 2016, Garay et al., 2019c, Garay et al., 2019e)

El comportamiento del fuego, o el conjunto de efectos de carácter físico y mecánico que se observan en el ambiente afectado por la propagación de aquel (Castillo et al., 2013), es el principal indicador que permite evaluar la conflictividad de los incendios y su grado de destrucción. En este sentido, en gran parte de los ecosistemas dominados por alta carga de vegetación combustible, su continuidad y bajo contenido de humedad, originan mayores niveles de energía liberada y la posibilidad de generar eventos de fuego más agresivos en la medida que éstos interactúan con condiciones meteorológicas favorables para su expansión. Esto se ha visto especialmente en incendios que se propagan en vegetación de tipo mediterránea, y que producto de la marcada estacionalidad y los factores descritos anteriormente, provocan mayores niveles de liberación de energía, un microclima especialmente favorable para el rápido avance de las llamas y mayores dificultades para las labores de extinción. La literatura actual describe a este tipo de incendios como de sexta generación, refiriéndose a eventos de gran magnitud, de rápida propagación y cuantiosos daños ambientales, económicos y sociales. Un ejemplo de lo anterior ha sido el estudio de Bowman et al., (2018), quienes evaluaron los niveles de intensidad del fuego desde medios satelitales, evidenciando montos de energía muy superiores a eventos habituales para la zona de estudio, en este caso en Chile Central. Este fenómeno se repite cada vez con mayor frecuencia en otras regiones mediterráneas, y más cercanas a zonas de interfaz urbano-forestal (Stewart et al., 2007, López, 2009, Herrero et al., 2012, Saavedra 2013).

El Ministerio de Vivienda y Urbanismo (MINVU), entidad pública responsable de las políticas públicas y la planificación territorial en Chile, ha enfatizado algunos aspectos no inclusivos del problema, como la calificación energética de viviendas que tiene carácter obligatorio, y la construcción sustentable que aún se presenta como voluntaria (Ministerio de Vivienda y Urbanismo. (2016). A pesar de ello, aún existe debilidad dada por la escasa fiscalización y regulación, así como sobre la integración de requisitos especiales para infraestructuras ubicadas en áreas de riesgos específicos como lo hace la normativa internacional (NFPA, 2018; AUSTRALIAN STANDARD®. AS3959, 2009) y que deberían

ACE, 16 (46) CC BY-ND 3.0 ES | UPC Barcelona, España | Viviendas ubicadas en áreas de riesgo de incendios

forestales de interfaz. Un análisis territorial y normativo desde Chile. DOI: http://dx.doi.org/10.5821/ace.16.46.9523 
corresponder a la concesión de permisos de edificación y las recepciones finales de todo tipo de obras edificadas. Existe, por ello, una brecha enorme y no cubierta con fundamentos técnicos que permitan avalar y modernizar las actuales regulaciones.

En muchas ocasiones, como es el caso de localidades en la comuna de San José de Maipo, Región Metropolitana de Chile, por ejemplo, las viviendas en zonas de interfaz urbano forestal, tienen una alta composición o son de madera en su totalidad y no han sido fabricadas bajo estándares que brinden la seguridad necesaria (Garay et al., 2019a; Garay et al., 2019b). En tales circunstancias, se podría establecer que cada residente es responsable del aseguramiento de su propiedad, lo cual abre espacios para plantear la posibilidad de mejorar la normativa actual (Garay et al., 2018). Sin embargo, como lo evidencian los hechos, la precariedad y vulnerabilidad frente a la exposición al peligro son una constante frente a eventos que desencadenan desastres, del mismo modo que en otras zonas del país.

Las experiencias preventivas vivienda hacia adentro y vivienda hacia afuera, se deberían traducir, en consecuencia, en dos sentidos. La reducción de la carga de combustible y su continuidad, particularmente en los puntos críticos en donde el fuego incrementa su actividad. Para ello se utilizan los planes de manejo de las áreas forestales y agrícolas (NFPA 2018, AUSTRALIAN STANDARD®. AS3959, 2009, CONAF, 2015). El problema es que, en Chile, aunque se divulgan las medidas a tomar, sólo se establecen como recomendaciones las de CONAF (2015) y no se vinculan a las normativas constructivas por parte del MINVU, a diferencia de las normas internacionales que son obligatorias.

En general, la resistencia y durabilidad de la madera frente al fuego, puede ser controlada con la agregación de masividad, otros materiales incombustibles o por compartimentación (NCh1913, 1988; Pérez, 2016; González, et al., 2016; Ministerio de Vivienda y Urbanismo, 2014). Ello plantea en consecuencia, la necesidad de incorporar evaluaciones e indicadores integrados de vulnerabilidad estructural frente al impacto de los incendios forestales. Un ejemplo, corresponde al índice de Prioridad de protección (IPP) e Índice integrado de Seguridad (IIS) - creados para evaluar infraestructura crítica (Garay et al 2018; Castillo et al., 2020)- y en consecuencia, otorgar referencias más sólidas para diseñar viviendas nuevas, según su nivel de exposición, así como producción de madera nativa y otras exóticas, estructurales y no estructurales, conjuntamente con la fabricación de elementos constructivos que cumplan requisitos estructurales y de resistencia al fuego.

La resiliencia, entendida como parte de las capacidades y atributos de la comunidad, esto es memoria institucional, aprendizaje innovador y conectividad, a su vez, es una cualidad potencial y posible para adaptarse a los cambios en el entorno, aunque el evento que desencadena un desastre sea de enorme magnitud. Este atributo, presente en medidas estructurales y no estructurales, es clave para enfrentarlos, como lo describe Longstaff et al., (2010) y es actualmente, un concepto que se trata de sobreponer a la vulnerabilidad como lo investiga Fisher et al., (2013), en instalaciones de infraestructura crítica encuestadas por el programa de Protección de infraestructura crítica mejorada (ECIP) del Departamento de Seguridad Nacional de EE. UU y donde queda en evidencia, la alta interdependencia entre el sector público y privado. En efecto, las empresas aseguradoras han ido replanteando sus pólizas a sus clientes, a raíz de la mayor frecuencia de eventos intensos y catastróficos.

El propósito de esta investigación, es el aportar antecedentes sobre la aplicabilidad de nuevas normas que permitan elevar el nivel de seguridad en viviendas expuestas al impacto de los incendios forestales, como también integrarlas a la normativa actualmente vigente en Chile. La multi factorialidad de un evento que desencadena un desastre, como los incendios forestales, lleva a comprender que las propuestas acá enunciadas, no garantizan la exclusión del problema global de incendios extremos que se suceden en las áreas de interfaz. En consecuencia, el principal aporte

ACE, 16 (46) CC BY-ND 3.0 ES | UPC Barcelona, España | Viviendas ubicadas en áreas de riesgo de incendios 
corresponde a la formulación de mejores referencias para el planeamiento e implementación de nuevas medidas para una mejor preparación al impacto de los incendios forestales, juntamente con la comprensión del peligro en el que se habita, lo cual permite un estado previo de alerta y reacción más adecuada para la comunidad.

El área de estudio, posee instrumentos básicos de planeamiento del territorio local, pero aquellos no recogen de manera específica la vulnerabilidad geográfica del problema de los incendios forestales. Se propone fortalecer las normas de ordenanza municipal, además de otros aspectos, mediante prescripciones técnicas para el mejoramiento en el grado de preparación frente a incendios para la infraestructura ya existente, como también las áreas aledañas que podrían ser parte de un sistema de mayor extensión para actividades preventivas, incluyendo la prohibición de uso habitacional, si ello es recomendable.

\section{Antecedentes}

Tanto el Marco de Acción de Hyogo como el Marco de Sendai para la Reducción del Riesgo de Desastres 2015-2030, se consideran referencias oficiales y aceptadas en la comunidad internacional para el fortalecimiento de la gobernanza, vinculada esencialmente a la generación de objetivos, planes, competencia, directrices y coordinación en los sectores, así como a la participación de los actores pertinentes (ONU, 2015, p. 17). En un contexto más ligado al ambiente, y de acuerdo con lo expresado en NFPAJL, (NFPAJL, 2019a), los incendios forestales, son un fenómeno natural, normal y dinámico que ocurre de manera estacional en gran parte de Norteamérica. Como tal, obedece a las leyes de la física y sólo puede existir y crecer con combustible, calor y oxígeno. Mientras que un incendio forestal puede conducirse con un patrón aparentemente aleatorio de consumo de combustible debido a la topografía y a las condiciones climáticas, especialmente el viento.

Dado que la destrucción de viviendas está directamente relacionada con las condiciones de las mismas en particular y con todo lo que las circundan dentro de los 100 a 200 pies (30 a 61 metros) -área denominada Zona de Ignición de la vivienda-, en general, queda a criterio y posibilidades del propietario, para el caso nacional, efectuar los cambios recomendados en el programa de comunidades protegidas.

En Estados Unidos, el programa de Comunidades Firewise, invita a los vecinos a trabajar juntos para reducir el riesgo de los incendios forestales. Es así que más de 500 comunidades en 38 Estados, han aprendido de los mitos relacionados con los incendios forestales y han enfrentado la realidad de su situación. Se organizan en comités de residentes y cuentan con la ayuda de profesionales de incendios y silvicultura, identifican los factores de riesgo de incendios forestales para sus comunidades, desarrollan planes de acción, y comienzan a actuar en las áreas problemáticas. Limpian la maleza y los residuos vegetales, los trozan, y deciden qué hacer con ellos; reemplazan techos inflamables, y acondicionan los garajes; además crean proyectos de retro instalación y mantenimiento para dar respuesta a sus riesgos particulares. La existencia de las normas NFPA (101, 703, 1141, 1144 y 5000), actúan en esa dirección, promoviendo la conformación de espacios protegidos. A modo de ejemplo, las normas 1141 y 1144 recomiendan 30 pies (9 metros) como mínimo para remover deshechos y reducir el volumen de vegetación viva. Esto resulta de experimentos de incendios en donde los investigadores quemaron grandes árboles para crear un muro de fuego para ver cuánto tiempo tardaba en encenderse un muro de madera, y a cuántos pies de distancia. Recién a los 9 metros de distancia, no había ignición la mayoría del tiempo, sólo un poco de carbonización, dado que las grandes llamas quemaban el área rápidamente.

ACE, 16 (4.6) CC BY-ND 3.0 ES | UPC Barcelona, España | Viviendas ubicadas en áreas de riesgo de incendios

forestales de interfaz. Un análisis territorial y normativo desde Chile. DOI: http://dx.doi.org/10.5821/ace.16.46.9523 
Por lo anterior, las Comunidades Firewise en Estados Unidos, pueden servir de ejemplo, pues se hallan convirtiendo sus vecindarios en lugares más seguros, con reglamentaciones formales, adoptadas por muchas municipalidades en sus ordenanzas para la disposición de vegetación, de protección contra incendios y normas de autorización. Además, subdivisiones recientemente desarrolladas, pueden hacer uso de estas normas no sólo para el diseño, sino para que asociaciones comunales se hagan responsables del crecimiento y mantenimiento a largo plazo de la subdivisión.

Sin embargo, falta instruir a los residentes en la noción de "reforzar" viviendas y otras estructuras, por ejemplo sellando grietas, fisuras y otras áreas donde las brasas de un incendio forestal transportadas por el viento pueden quedar atrapadas y provocar un incendio. La ausencia de viviendas reforzadas, como otra condición o factor, puede resultar en la destrucción de miles de estructuras por causa de incendios forestales.

El informe Westhaver (NFPAJL, 2019b), preparado para el Instituto de Reducción de Pérdidas Ocasionadas por Catástrofes de Toronto, determinó que la pérdida de estructuras en el incendio no fue aleatoria, sino dependiente de la preparación de las viviendas, según lo establecido por los lineamientos descritos en FireSmart (programa de preparación para incendios forestales de Canadá), similar al programa Firewise de NFPA (creado en Estados Unidos en 1985, tras el mega incendio que afectó a un importante sector poblacional en California). Según el informe, el $81 \%$ de las viviendas que sobrevivieron al incendio tenían certificación de riesgo FireSmart de baja a moderada, lo que indica que estaban debidamente preparadas para un incendio forestal y todas las que sobrevivieron a pesar de la exposición extrema al fuego, tenían una certificación de riesgo bajo. Por el contrario, la mayoría de las viviendas que fueron destruidas, tenían certificaciones de riesgo Firesmart de alto a extremo. Este informe concluye que puede haber un "talón de Aquiles" o una debilidad aun habiendo cumplido con todos los otros lineamientos de FireSmart (GMV, 2012).

En relación a la propagación del fuego, los incendios atraviesan urbanizaciones principalmente en los jardines y alrededores, pero también por la continuidad del combustible forestal puede hacerlo por el interior de las viviendas, ello, dependerá de los materiales de construcción (NFPA 1144, NFPAJL, 2017, BCN, 2017). Si son resistentes al fuego, éste solo entrará por las aberturas que encuentre a su paso: puertas, ventanas, rendijas, sistema de ventilación. No sólo las llamas pueden comenzar la ignición en el interior de una vivienda, también las pavesas que genera el incendio. Entre la normativa más relevante de mencionar en protección de edificaciones está el Código de Construcción de Australia (BCA) que forma parte del Código Nacional de Construcción y proporciona la normativa de construcción de edificios en ese país (BCN, 2017). Se establecen requisitos para abordar los objetivos y las declaraciones funcionales en relación con los elementos de un edificio. Específicamente, el Estándar Australiano para la Construcción de edificios en áreas propensas a incendios forestales. En ella, se definen seis niveles de ataque en áreas forestales (BAL) categorías, a saber, BAL-LOW, BAL12.5, BAL-19, BAL-29, BAL-40 y BAL-FZ. Estas categorías se basan en los umbrales de exposición al flujo de calor, las áreas de riesgo de incendios forestales (AUSTRALIAN STANDARD®. AS3959, 2009), siendo relevante su cumplimiento para la construcción en zonas de peligro y para el establecimiento de vías expeditas para la evacuación e ingreso de los cuerpos de combate al fuego, entre otros.

A medida que el número BAL aumenta, implica que la severidad del incendio forestal es mayor por el ataque de las brasas, el calor radiante y el contacto directo con las llamas que también aumentan. El número asociado con el BAL representa el calor radiante máximo expresado en kilovatios por metro cuadrado de la superficie del edificio que se supone está también expuesto. La gravedad de un incendio forestal o BAL está influenciada por el índice de peligro de incendios forestales, el tipo de vegetación, la pendiente de la tierra bajo la vegetación y la distancia a la que el edificio está separado de la vegetación.

ACE, 16 (4.6) CC BY-ND 3.0 ES | UPC Barcelona, España | Viviendas ubicadas en áreas de riesgo de incendios

forestales de interfaz. Un análisis territorial y normativo desde Chile. DOI: http://dx.doi.org/10.5821/ace.16.46.9523 
El estándar, usa el BAL como la base para establecer los requisitos de construcción para mejorar la protección de los elementos del edificio de ataque de incendios forestales. Es necesario determinar los BAL antes de utilizar los requisitos de construcción prescritos. Ver Tabla 1.

Tabla 1. Estándar Australiano para la Construcción de edificios en áreas propensas a incendios forestales BAL. AS3959-2009

\begin{tabular}{|l|l|}
\hline Exposición & $\begin{array}{l}\text { Descripción de los niveles previstos de ataque de incendio forestal } \\
\text { bajo el Estándar australiano }\end{array}$ \\
\hline BAL-LOW & $\begin{array}{l}\text { El bajo riesgo de ataque de incendios forestales no garantiza requisitos específicos de } \\
\text { construcción }\end{array}$ \\
\hline BAL-12.5 & $\begin{array}{l}\text { Posibilidad de ataque de brasas. } \\
\text { con un flujo de calor creciente no mayor a 19kW / m2 }\end{array}$ \\
\hline BAL-19 & $\begin{array}{l}\text { Aumento de los niveles de ataque de brasas y pavesas ardiendo transmitidas por el viento, } \\
\text { juntos con un flujo de calor creciente no mayor a } 29 \mathrm{~kW} / \mathrm{m} 2\end{array}$ \\
\hline BAL-29 & $\begin{array}{l}\text { Aumento del nivel de ataque de brasas y pavesas ardiendo transmitidas por el viento, junto } \\
\text { con aumento del flujo de calor no mayor a } 40 \mathrm{~kW} / \mathrm{m} 2 \mathrm{y} \text { una mayor probabilidad de exposición } \\
\text { a las llamas. }\end{array}$ \\
\hline BAL FZ & $\begin{array}{l}\text { Riesgo de exposición directa a las llamas de un frente de fuego, ataque de brasas y flujo de } \\
\text { calor de más de } 40 \mathrm{~kW} / \mathrm{m}^{2}\end{array}$ \\
\hline
\end{tabular}

Fuente: AS3959-2009.

En Chile, aunque ocurren desastres asociados a incendios forestales como el que afectó a la región del Maule, especialmente a la localidad de Santa Olga, en el 2017, aún existe la oportunidad de modificar desde conductas reactivas hacia conductas preventivas, basadas en la evidencia (Micheletti, Pacani y Pisani, 2020). A pesar de que estos autores realizan un análisis detallado de la gestión de diversos actores, abordando el problema desde la reconstrucción, no informan respecto a la precariedad del habitar en áreas de riesgo (Garay et al., 2018, Garay et al., 2020), de la dispersión de las viviendas en un amplio territorio, de la falta de recepción de obras y edificaciones en el municipio, de las ampliaciones irregulares y otros aspectos que aportaban negativamente mucho antes que el incendio llegara a este poblado. (Programa de Reducción de riesgos y desastres, 2020a y b).

Muchas veces, el análisis ex post, evidencia un problema de enfoque, casi exclusivamente ligado a la existencia de plantaciones o bosques, sin integrar adecuadamente la composición del paisaje, la infraestructura y la peligrosa aproximación de zonas habitadas (Galilea, 2019; Dombeck, et al., 2004; Chaz, 2013; Flannigan, et al., 2012 y CFA, 2012, Fernández Aragón, I. et al. 2021). Tras la experiencia, se comienza a actuar tratando de establecer distancias más adecuadas, sin llegar todavía a establecer indicaciones o protocolos hacia las acciones de mitigación y protección de las propias viviendas, incluyendo el despeje de áreas cercanas, materialidades y otros temas específicos que articulen y compartan responsabilidades también hacia los habitantes que tendrían que organizarse si viven en estas áreas. Tampoco se revisa la incidencia de los instrumentos de ordenamiento territorial.

Las características biofísicas de un lugar no solo traen variaciones en los peligros naturales, sino que también influyen en la percepción y respuesta asociada de las personas al peligro, Khan et al., (2012), explora las diferencias entre la susceptibilidad física y percibida a los peligros naturales y cómo esto afecta la respuesta de las personas a un peligro y concluye que el mapeo de la susceptibilidad física y percibida a los peligros en el espacio, la comprensión de su relación y, en última instancia, la reducción de la brecha entre la percepción y la realidad pueden contribuir al manejo efectivo de los peligros.(Programa de Reducción de riesgos de Desastres 2020a y b).

ACE, 16 (4.6) CC BY-ND 3.0 ES | UPC Barcelona, España | Viviendas ubicadas en áreas de riesgo de incendios

forestales de interfaz. Un análisis territorial y normativo desde Chile. DOI: http://dx.doi.org/10.5821/ace.16.46.9523 
Así, las políticas públicas para gestionar el territorio en su complejidad en cuanto a lugares con múltiples especificidades, más bien han sido reformuladas con una ausencia de un enfoque de sustentabilidad mantenida y creciente en el tiempo (Pavez, 2013; Olavarría, 2010; Balbontín, 2020).

Tras los incendios forestales que marcaron una alta notoriedad en 2017 (Oficina Nacional de Emergencia del Ministerio del Interior y Seguridad Pública, ONEMI, et al., 2018) y que han continuado ocurriendo los veranos sucesivos, se ha instalado la discusión del problema y, por ejemplo, las empresas forestales implementan el programa Firewise en 17 sectores prioritarios de las Regiones del Maule, Biobío, Araucanía y Los Lagos, seleccionados conforme a los criterios establecidos por municipios, ONEMI, CONAF, Bomberos, CORMA y Juntas de Vecinos entre otros. (González, 2017; Lignum, 2016).

Si bien la modificación de normas de construcción es aún débil por ser de carácter voluntario (Macari 2015; Ministerio de Vivienda y Urbanismo, 2016, Ministerio de Vivienda y Urbanismo 2018; Ministerio de Vivienda y Urbanismo 2019), se ha puesto la preocupación en la causalidad como factor humano preponderante, reiterando medidas y conductas adecuadas con el entorno próximo a viviendas (CONAF, 2015; CONAF 2020). Como, por ejemplo, no tirar basura inflamable, arrojar cigarros encendidos, apagar mal las fogatas, etc., pretendiendo que estas medidas ayuden a mitigar y reducir los riesgos accidentales e intencionales.

La Figura 1, muestra un esquema de los puntos donde se pueden alojar brasas y pavesas en una edificación. Su inspección y protección resulta esencial en la micro escala. En casas antiguas, permite reducir la vulnerabilidad al ataque. El diseño de nuevas construcciones debiese minimizar los riesgos de accesibilidad de pavesas y brasas según la zona de instalación, del mismo modo que se está implementando la calificación energética de viviendas según zonas térmicas que, como se mencionó, no incluye protección contra incendios desde afuera, Algunos puntos críticos a considerar son:

- Esquinas reentrantes

- Líneas complejas de techo

- Brechas entre materiales de construcción (paredes y techo)

- Espacio subterráneo no cerrado

Figura 1. Estándar Puntos de Ingreso de brasas y pavesas

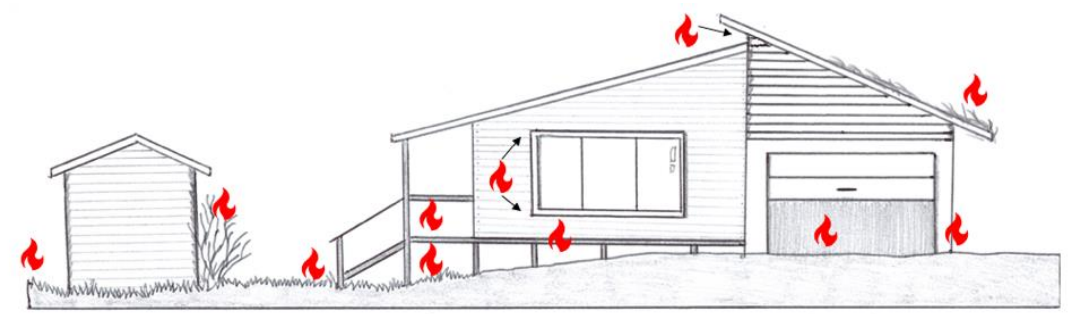

Brechas entre material de construcción paredes y techos)

Espacio subterráneo no cerrado

Fuente: CFA (2012)

Observando, esta imagen, cabe preguntarse, ¿Por qué, si ya existe suficiente conocimiento tanto de la seguridad necesaria de las construcciones como de su entorno, no se toman medidas para evitar desastres? La respuesta que subyace, aunque incomoda, es que la mayor parte de la responsabilidad es de los privados, en cuanto al tipo de viviendas que adquieren, donde la instalan, que asesoramiento buscan para hacerlo, sumado a esto, los permisos de edificación son entregados por los municipios, quienes no han terminado de incluir (o actualizar) las áreas de riesgo en los planes reguladores (Romero 2009), incluidas ahí las áreas de interfaz urbano forestal. En este escenario, el problema en Chile, con aristas múltiples (Garay et al., 2020) no se resuelve, a pesar de la realidad. 
Existe evidencia científica de un futuro con mayor cantidad e intensidad de incendios forestales. Es positivo que la investigación y la modelización sirvan de advertencia temprana del problema, lo que da tiempo para tomar medidas que permitan adaptación a estos (FNPAJL, 2019b). Es posible, además, estudiar las causas, los efectos, y por sobretodo, anticipar mejor cómo las ciudades, pueblos y vecindarios pueden prepararse cuando sean confrontados con el fuego. Por otra parte, el aumento de los incendios forestales en el paisaje en el presente y futuro obligará a las agencias de manejo de fuego a re-evaluar la política y la estrategia. Todas las áreas forestales no pueden ser protegidas contra los incendios, y muchas otras de alto valor que se manejan con una política de exclusión del fuego, se verán amenazadas por los incendios forestales.

Por todos estos antecedentes, se expone el análisis de acciones, normativas y regulaciones nacionales e internacionales posibles de implementar de acuerdo con las condiciones de vulnerabilidad del habitar en localidades de la comuna de San José de Maipo, una extensa área que forma parte de la Región Metropolitana, Chile, yendo desde lo general, la macro escala, hasta lo particular, la microescala, con el propósito de poner este análisis a disposición de tomadores de decisiones.

\section{Material y método}

\subsection{Material}

El estudio se concentró en el territorio de la Comuna de San José de Maipo (Figura 2). En la comuna, existen 23 localidades que albergan estructuras internalizadas en zonas arboladas y que poseen actividad turística. (Ilustre Municipalidad de San José de Maipo, 2010a, 2010b, 2016a, 2016b).

Figura 2. Comuna de San José de Maipo

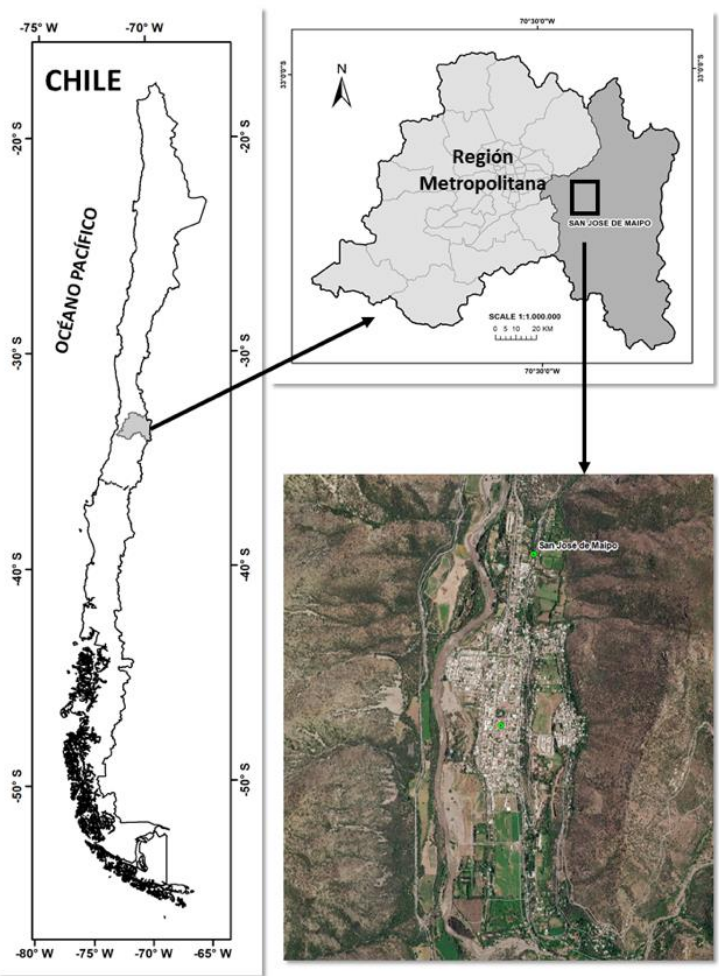

Fuente: Elaborado con datos de SIT CONAF (2019).

ACE, 16 (46) CC BY-ND 3.0 ES | UPC Barcelona, España | Viviendas ubicadas en áreas de riesgo de incendios

forestales de interfaz. Un análisis territorial y normativo desde Chile. DOI: http://dx.doi.org/10.5821/ace.16.46.9523 
El territorio en cuestión, posee 6.926 viviendas, de las cuales 5.132 están ocupadas con moradores presentes, 432 con moradores ausentes, 284 desocupadas por motivo de venta, en espera de arriendo o abandonadas, 1.002 corresponden a edificaciones particulares de temporada, y, por último, 76 corresponden a viviendas colectivas (INE, 2018).

\subsection{Método}

El territorio se analizó físicamente desde el punto de vista de su condición de vulnerabilidad, utilizando para ello variables estructurales que dieron cuenta del riesgo de incendios forestales, del peligro en la propagación del fuego, y de los daños potenciales (ambientales y sociales). Para ello, se establecieron tres niveles de percepción geográfica: la macroescala (1:500.000) que revisa los aspectos territoriales a nivel de toda la comuna, luego la mesoescala (1:50.000) que profundiza los efectos de los incendios forestales de interfaz, para finalmente analizar la situación normativa de las viviendas instaladas en estas zonas y sus características estructurales y de emplazamiento (casa hacia adentro y casa hacia afuera (microescala, nivel 1:20.000 y menor), poniendo el énfasis en las vulnerabilidades (vinculadas a lo normativo y regulatorio).

El nivel a mesoescala ha sido definido en el contexto de la metodología de evaluación frente a incendios forestales definidas por Castillo et al. (2013), quienes analizaron la interfaz del puerto de Valparaíso siguiendo estos tres niveles de percepción geográfica. (Figura 3). El nivel a microescala ha sido propuesto a partir de la metodología de Garay et al., (2018) y considerando las regulaciones tanto nacionales como internacionales.

Figura 3. Percepción geográfica de las tres escalas de análisis territorial

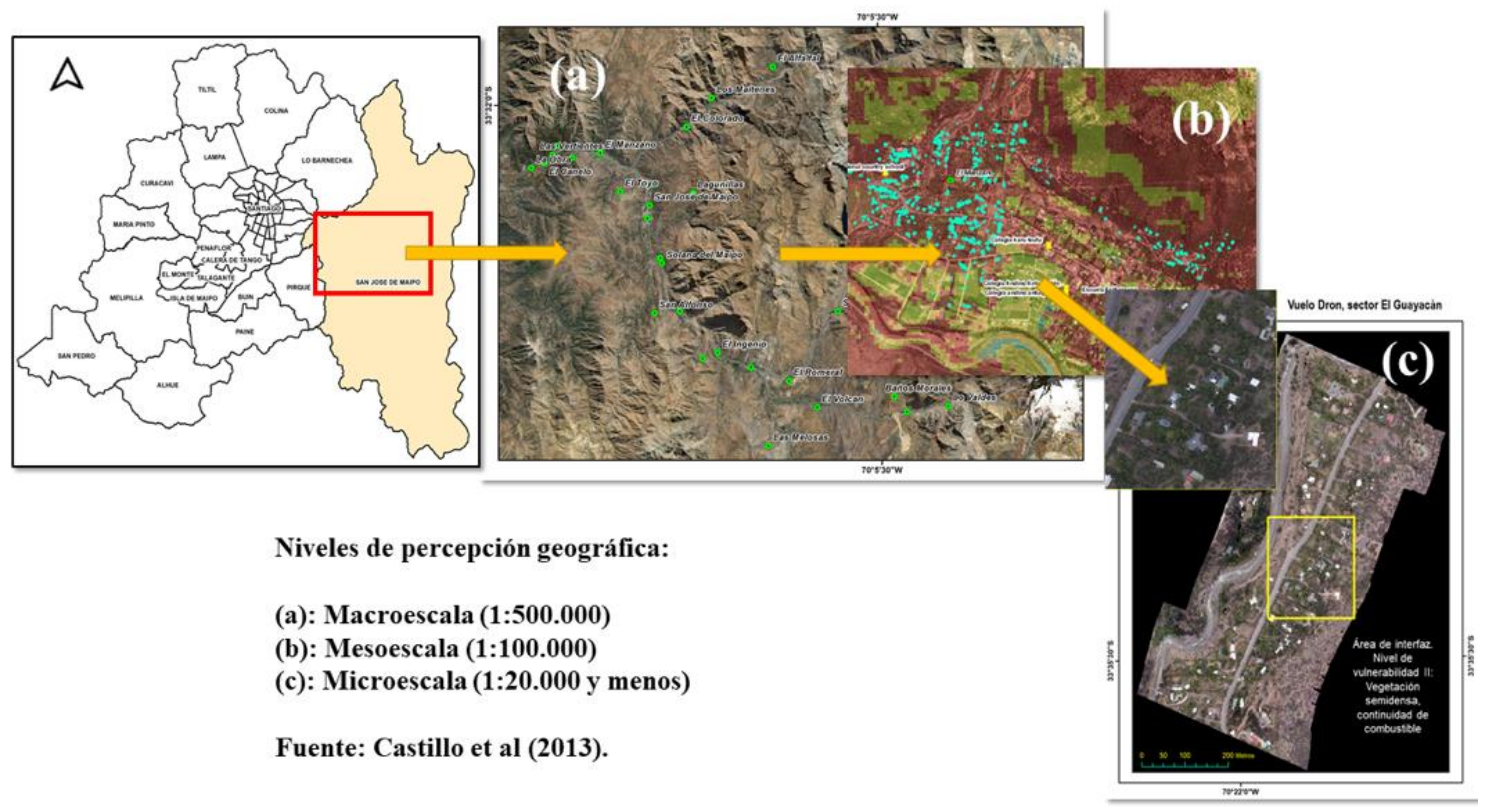

Nota: Planteadas para la vulnerabilidad territorial en viviendas expuestas al impacto potencial de nuevos incendios forestales.

Fuente: Elaborado con datos de Castillo et al., 2013, SIT CONAF (2019) y Laboratorio de Incendios Forestales (FCFCN).

ACE, 16 (4.6) CC BY-ND 3.0 ES | UPC Barcelona, España | Viviendas ubicadas en áreas de riesgo de incendios 


\section{Resultados}

\subsection{Macroescala}

En la macroescala, él área de afectación comunal (Ilustre Municipalidad de San José de Maipo, 2010a, 2010b, 2016a, 2016b) para este estudio, implicó caracterizar la continuidad del combustible, así como de los escenarios de incendio.

Así mismo, esta dimensión permite anticiparse, puesto que para la prevención se requieren sistemas de autoprotección de las zonas urbanas, ya que el aumento del riesgo de incendio y de la peligrosidad en la interfaz se debe a la presencia de viviendas y actividades en áreas de bosque, lo que supone un mayor riesgo implícito de ignición. La vulnerabilidad de las viviendas es un indicador de riesgo y/o peligrosidad ante un incendio (CONAF, 2020). La amenaza del humo para los habitantes de la interfaz es limitante que debe tenerse en cuenta, así como las vías de accesibilidad y las vías de escape estrechas y/o únicas son, con frecuencia, características de las zonas de interfaz.

\subsection{Mesoescala}

En el dominio de la mesoescala, el nivel de la urbanización que incluye el interfaz urbano forestal para este estudio, se consideran tres componentes: Las características del interior de las viviendas y vegetación; la zona perimetral; los terrenos exteriores que lo rodean. Involucra a localidades, barrios completos y viviendas aisladas o continuas. Es importante vigilar otras amenazas subyacentes como la existencia de actividades productivas, comerciales, militares u otras que puedan aumentar la peligrosidad por acumulación de material combustible, un ejemplo de ello son los servicios de suministro de combustibles.(Programa de Reducción de Riesgo de Desastres 2020a y b)

Las medidas preventivas pretenden transformar esta especie de tejido, en una zona de transición donde existen oportunidades para la extinción de incendios y adaptación al paso del fuego. Para ello se controla el combustible, se mejora la accesibilidad y se incrementa la disponibilidad de agua y potencialmente la eliminación de fuentes de peligro adicionales.

La vegetación en el interior de la urbanización tiene una función primordial cuándo el incendio impacta y cómo este se traslada, cómo se generan pavesas y finalmente cómo el fuego llega hasta las viviendas. Se precisa que progresivamente se vayan estableciendo medidas de autoprotección. La conformación en estas viviendas crea patrones, los cuales varían según aquellas estén aisladas o diseminadas y rodeadas de vegetación. Una situación extrema ocurre cuando hay muchas viviendas con vegetación arbórea entre ellas, el fuego va a progresar al interior afectando también el humo y las pavesas.

La acumulación de combustibles en los alrededores, juegos de terrazas, techos inflamables y edificaciones en madera, así como la presencia de setos o arbustos, son aspectos clave en la mesoescala. De acuerdo a la energía radiante esperada y el umbral máximo soportado por los bomberos en un punto dado del territorio, es posible identificar la extensión e intensidad requerida para el tratamiento de los combustibles en el interior, en el perímetro y en el exterior de la urbanización.

Algunos jardines tienen gran carga de combustible, lo que dificulta o imposibilita la defensa de las viviendas. De hecho, en muchos casos, no hay un espacio defendible en el que se pueda operar con seguridad. En esta escala, podrían aplicarse los aprendizajes y resultados obtenidos de la revisión de las normas norteamericanas, canadienses y australianas.

ACE, 16 (4.6) CC BY-ND 3.0 ES | UPC Barcelona, España | Viviendas ubicadas en áreas de riesgo de incendios forestales de interfaz. Un análisis territorial y normativo desde Chile. DOI: http://dx.doi.org/10.5821/ace.16.46.9523 
Se analizó a su vez, el estado del instrumento de ordenación de la comuna, para el caso, su Plan Regulador Comunal y la relación e influencia de éste, en las escalas de análisis. La comuna, no posee un plan propio y se rige por el Plan Regulador Intercomunal de Santiago elaborado en 1994. Esta condición y atraso en este instrumento, es un factor no estructural altamente incidente en el problema y las vulnerabilidades asociadas (Arteaga y Tapia, 2014). Aunque, para ser justos, han creado una ordenanza municipal frente a los incendios forestales, que, entre otras medidas, establece la responsabilidad de las empresas eléctricas sobre el despeje de vegetación del cableado público, así como de la mantención de jardines de los propios vecinos, aunque aún no se percibe un nivel importante de fiscalización.

\subsection{Microescala}

La microescala es del dominio del propietario y allí se puede hacer mucho. Los jardines son una oportunidad para la prevención: limitando la cantidad de carga de elementos finos, controlando el tipo de vegetación con alto nivel de humedad de plantas adyacentes y controlando la carga del sotobosque. Asimismo, se pueden tomar medidas respecto a la infraestructura de las viviendas y otras construcciones aledañas como galpones, cobertizos, entre otros.

Figura 4. Zonas de acción frente a incendios forestales de interfaz

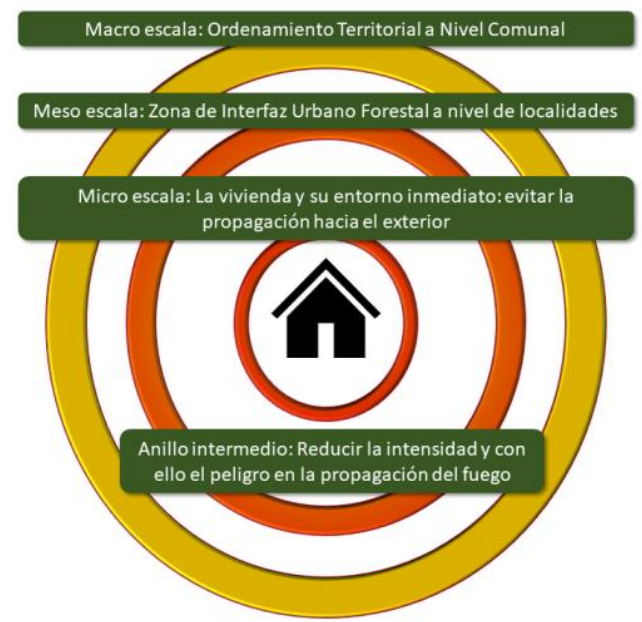

Fuente: Elaboración Propia, usando Casa Segura de CONAF (2015) y Guía metodológica de actuaciones de prevención, defensa y autoprotección en interfaz urbano forestal (2014).

Entre las consideraciones sobre la vegetación, se debe contemplar que la humedad de las plantas está directamente relacionada con las rutinas de riesgo y tratamientos que se realizan. Los setos, tienen un rol primordial para reducir o incrementar la intensidad y propagación del fuego.

Se requiere un gran esfuerzo para llevar a cabo medidas de prevención, así como otras de concienciación, sensibilización, acción en el territorio, formación y comunicación a los vecinos. La percepción del riesgo en la comunidad es el éxito en la prevención del interfaz urbano forestal, ya que la prevención es un esfuerzo común.

El tiempo de permanencia de las llamas en un incendio forestal dependerá de la presencia de acumulaciones de combustible, los elementos constructivos inflamables y las vías de entrada de las llamas al interior de las viviendas, como principales factores que provocan la ignición de la estructura. La Figura 5, muestra un mapa con la modelación de incendio forestal de interfaz para la comuna de estudio, revelando que gran parte del territorio poblado está en alta prioridad de protección, es decir el $97 \%$ de las zonas pobladas, lo que incluye el trayecto de la única vía de circulación de la zona.

ACE, 16 (4.6) CC BY-ND 3.0 ES | UPC Barcelona, España | Viviendas ubicadas en áreas de riesgo de incendios 12 forestales de interfaz. Un análisis territorial y normativo desde Chile. DOI: http://dx.doi.org/10.5821/ace.16.46.9523 


\section{ACE Architecture, City and Environment}

E-ISSN $1886-4805$

Figura 5. Visión sinóptica de la vulnerabilidad del territorio en estudio bajo amenaza de incendios forestales

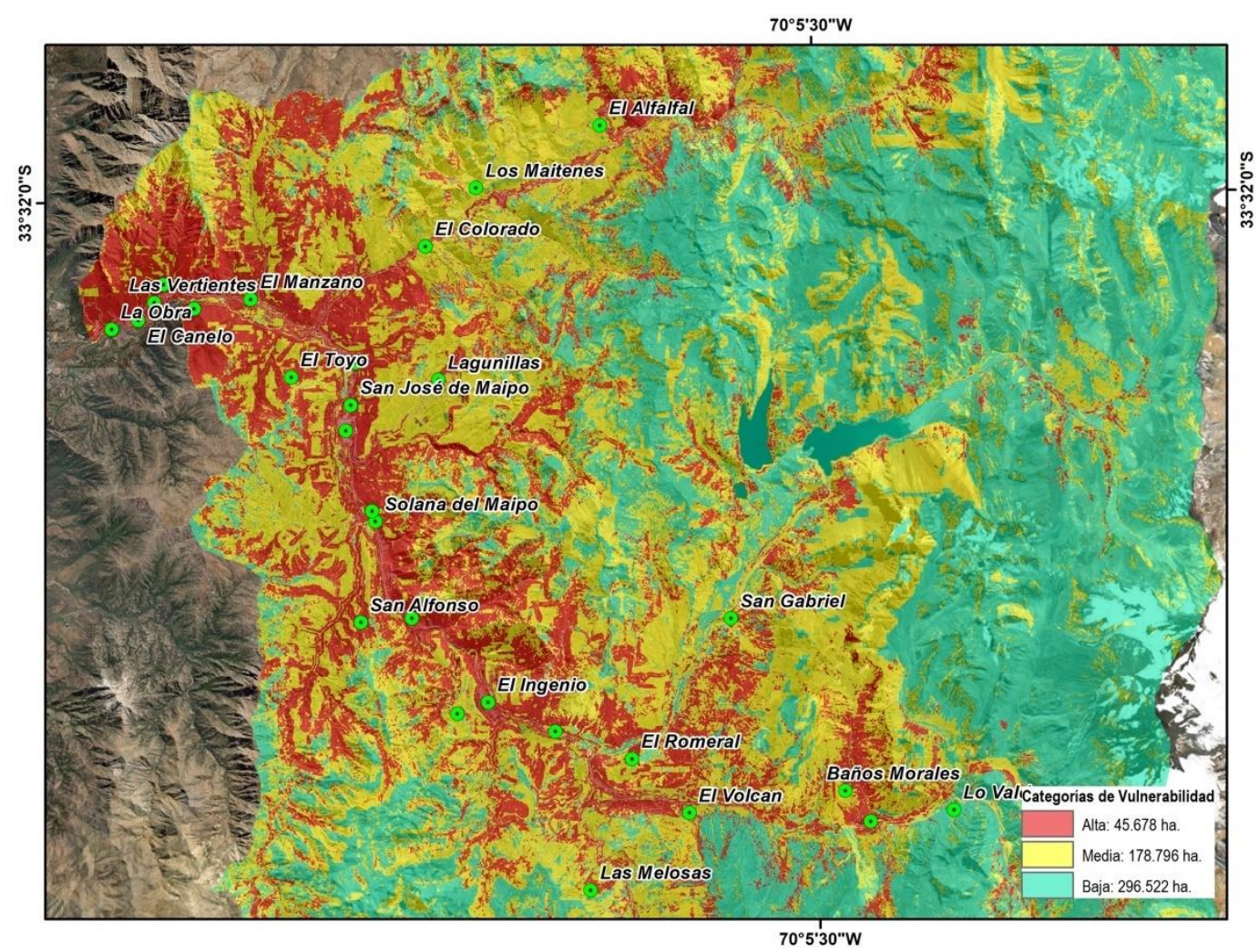

Fuente: Elaboración Propia en base a datos del Laboratorio de Incendios Forestales, Facultad de Ciencias Forestales y de la Conservación de la Naturaleza (FCFCN, 2019).

A pesar de múltiples evidencias de los beneficios del uso de la madera en la construcción, en Chile formalmente no se construye con este material de forma significativa; las cifras no sobrepasan el 18\% de lo registrado en materialidad para viviendas con subsidio del Estado (INE, 2019). Aunque se destacan los beneficios de este material, aún no ha sido suficiente, persistiendo la desconfianza en su homogeneidad y una visión negativa que vincula a este material con viviendas de emergencia, precariedad y pobreza. Aunque un mercado importante lo constituye la autoconstrucción -sistema muy común de construcción en Chile - segunda vivienda y ampliaciones, el abanico de oferta en ello, es muy amplio y variado, siendo provisto por oficinas de arquitectura, empresas inmobiliarias especializadas, fábricas de viviendas prefabricadas y una gran oferta de tipo informal a través de páginas web. Esta construcción, no es regulada ni fiscalizada, por lo que no existe un registro estadístico más ajustado a la realidad que dimensione el tamaño de este mercado y, de acuerdo con lo expresado por el propio Ministerio de la Vivienda, se trata de un negocio entre privados, por lo que, según las leyes y normas, es el profesional competente (arquitecto o constructor civil) firmante quien debe responsabilizarse. Sin embargo, este mercado que se presume importante por la frecuencia y existencia de este tipo de viviendas especialmente en zonas rurales y periurbanas del centro y sur del país, escasamente recurre a profesionales cuya firma avale la recepción final de las edificaciones en las direcciones de obras municipales, en donde debería existir la fiscalización, pero que en la mayoría de los casos no ocurre.

En contraposición a lo anterior, en Chile existen oficinas de arquitectura y empresas de prestigio que son proveedoras de construcciones en madera de alto estándar, qué de ser necesario, pueden incluso responder a estándares de resistencia al fuego más altos, así como, por ejemplo, aportar

ACE, 16 (4.6) CC BY-ND 3.0 ES | UPC Barcelona, España | Viviendas ubicadas en áreas de riesgo de incendios 
antecedentes al análisis de ciclo de vida de la madera en la construcción, como una comparación entre diferentes materiales y la madera, incluyendo la emisión de carbono. Este es un antecedente relevante en el mercado mundial de construcción en madera, donde se está tratando a este material como una solución altamente sustentable y para el cual se ha innovado e implementado soluciones constructivas eficientes, acorde con las necesidades de este siglo.

En el país, se ha avanzado por la vía de innovar en edificios de mediana altura en madera, basados en que se debe impulsar su aplicación en otros ámbitos(González et al 2016, . De esta forma, siguiendo una lógica similar, se resume lo esencial de la agenda pública del proyecto estratégico meso-regional cuyos objetivos se centran en impulsar el desarrollo de la industria, aumentar uso de la madera, valor agregado, tecnología y apoyo al fomento productivo. Así mismo, la política forestal estableció como eje estratégico, aumentar la productividad y duplicar la construcción de viviendas en madera, al 2035. Las acciones específicas han sido:

- Abordar brechas normativas

- Especialización de profesionales, trabajadores y empresas

- Certificación y control de calidad para uso en construcción

- Mejorar percepción del material por parte de los usuarios

- Los ejes estratégicos son la normativa, el control de calidad (rotulado de la madera), Capacitar y difundir, Desarrollar proyectos detonantes, diversificar soluciones

El fortalecimiento y actualización del marco normativo técnico, se estima esencial para consolidar el uso de la madera en la construcción (Centro UC de Innovación en Madera, 2019; Ministerio de Vivienda y Urbanismo, 2018), tanto en mediana altura en Chile, como para un uso seguro en edificaciones en áreas de riesgo de incendios forestales, esto es, aplicando modificaciones normativas que impacten también esto usos. Al desarrollar propuestas de modificación de la normativa sísmica y estructural, incluyendo CLT y Sistema Marco Plataforma, se estaría cumpliendo también la necesidad planteada o sería necesario, incluir nuevas disposiciones como, la generación de norma para cálculo de resistencia al fuego. Actualmente alrededor de 37 normas han sido actualizadas y que disminuyen las brechas detectadas (Ministerio de Vivienda y Urbanismo, 2019), aunque se deba volver a revisar si han sido suficientes y si en ellas se ha contemplado el lugar de emplazamiento de las edificaciones y sus riesgos asociados. En la tabla 2, se presentan algunos ejemplos de las normativas modificadas. Sin embargo, es necesario un detalle sobre medidas de seguridad específicas como resistencia al fuego de elementos estructurales y no estructurales, materialidad incombustible, no inflamabilidad, no toxicidad y opacidad de humos; aumento de masividad y cobertura con elementos incombustibles; también las limitaciones de uso de materiales plásticos y otros que aporten carga combustible, son aspectos de protección pasiva que pueden ser incluidos en una guía práctica que evalúe las edificaciones y conduzca a recomendaciones para disminuir su vulnerabilidad. La tabla 2 muestra los cambios normativos en curso, que no incluyen lo anteriormente expuesto, por eso es urgente su incorporación (Ministerio de la Vivienda y Urbanismo, 2019).

Tabla 2. Ejemplos de modificación normativa abordada en Chile

\begin{tabular}{|l|l|}
\hline NCh173:2008 & Madera - Terminología general desempleadas \\
\hline NCh174:2007 & Maderas - Unidades, dimensiones nominales, tolerancias y especificaciones \\
\hline NCh176/1:2003 & Madera - Parte 1: Determinación del contenido de humedad \\
\hline NCh630:1998 & Madera - Preservación - Terminología \\
\hline NCh631:2003 & Madera preservada - Extracción de muestras \\
\hline NCh755:1996 & Madera - Preservación - Medición de la penetración de preservantes en la madera \\
\hline NCh819:2012 & $\begin{array}{l}\text { Madera preservada - Pino radiata - Clasificación según riesgo de deterioro en servicio y } \\
\text { muestreo }\end{array}$ \\
\hline NCh2824:2003 & Maderas - Pino radiata - Unidades, dimensiones y tolerancias \\
\hline
\end{tabular}

Fuente: Ministerio de la Vivienda y Urbanismo (2019) e Institutito Nacional de Normalización (2019).

ACE, 16 (46) CC BY-ND 3.0 ES | UPC Barcelona, España | Viviendas ubicadas en áreas de riesgo de incendios 


\subsection{Incendio en edificaciones. Actualización de la Normativa en Chile}

Como se ha mencionado, la Ingeniería de protección contra incendios en aplicación estructural, se basa en una concepción científica que evalúa el riesgo de incendios al interior de los edificios, existiendo diferencias importantes cuando el fuego viene desde afuera. La secuencia de la Figura 6, expone evidencias de cómo se producen los incendios (a), como se consume la carga combustible y su declinación (b).

Figura 6. Concepción científica (a y b) para definir exigencias de resistencia normativa

a)

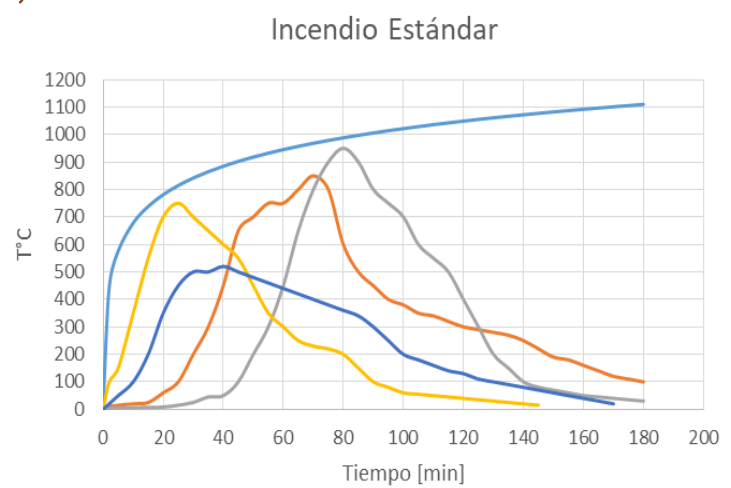

b)

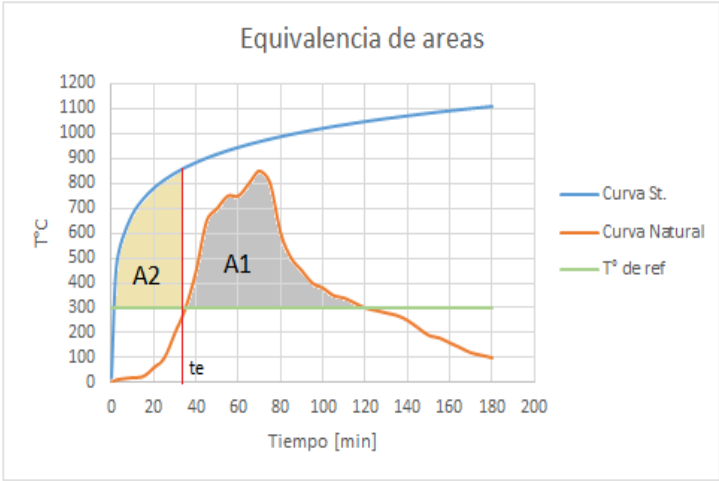

Fuente: Ministerio de Vivienda y Urbanismo 2014a, Ministerio de Vivienda y Urbanismo 2014b.

De acuerdo con lo que muestra la figura 6, es posible adaptar el objetivo primordial, usando el conocimiento para la aplicación de una estrategia de protección que considere tanto el establecer una zona segura, como la compartimentación y la resistencia al fuego de los materiales, cuando el incendio viene desde el exterior y puede ser de gran magnitud, como lo están siendo. De esta forma, un requerimiento F90 para un edificio de altura o frente a un incendio forestal, no pretende dar 90 min., de tiempo disponible para evacuar sino ese tiempo está considerado para soportar la extinción del incendio sin colapsar. Estableciéndose como premisa que el edificio no puede colapsar antes que se haya logrado la total evacuación de este. Por ello, las exigencias son mayores cuando se trata de edificios en altura y en locales de gran concurrencia de público, cuya lógica considera que el fuego se produce desde adentro del edificio(Ministerio de la Vivienda y Urbanismo 2014a, Ministerio de Vivienda y urbanismo 2014b) y no que provenga desde afuera, pero sí así fuese, al menos los edificios debiesen contemplar la protección externa en similares condiciones (NFPA 1144, Castillo et al., 2020, Garay et al., 2019).

Este antecedente es primordial para la elección de la materialidad, pero no implica que no se pueda usar madera, sino que ella, debería cumplir a igualdad de condiciones con la exigencia impuesta para otros materiales, si esto se cumple, su uso no es limitado.

\subsection{Anteproyecto de norma de cálculo de resistencia al fuego en madera}

Hay una gran oportunidad para enfrentar estos cambios normativos (Instituto Nacional de Normalización, 1997) y fortalecer la seguridad de edificaciones ubicadas o por instalar en áreas de riesgo de incendios forestales, ya que se está actualizando la metodología de cálculo que permite diseñar elementos y sistemas constructivos en madera en Chile en la norma chilena NCh1198 - 2 Madera - Construcciones en madera - Cálculo. Parte 2: Cálculo de estructuras expuestas al fuego, procurando mejorar la protección en edificios de mediana altura, sin embargo, como se indicó, está quedando fuera el análisis la protección cuando el fuego proviene del exterior y que se encuentra

ACE, 16 (4.6) CC BY-ND 3.0 ES | UPC Barcelona, España | Viviendas ubicadas en áreas de riesgo de incendios 15 forestales de interfaz. Un análisis territorial y normativo desde Chile. DOI: http://dx.doi.org/10.5821/ace.16.46.9523 
bien descrito en la normativa internacional de amplio uso en la construcción norteamericana, canadiense y australiana. Alcances de esta norma:

1. Regula el proyecto, análisis y diseño de construcciones de madera para la situación accidental de incendio y rige en conjunto con NCh 1198-1. NCh 1198-2 establece solo diferencias de complementos para el diseño bajo temperatura normal.

2. Trata únicamente la protección pasiva para la situación accidental de incendio. No trata los métodos de protección activa de protección contra incendios.

3. Rige para construcciones sobre las que se imponen exigencias específicas ante una solicitación de exposición al fuego, relacionadas con:

- evitar una falla prematura de la estructura (función resistente);

- Limitar la propagación del fuego (llamas, gases calientes, calor excesivo) sobre determinados sectores (función de compartimentación o confinante).

1. Contiene principios y reglas de uso para el diseño de estructuras respetando exigencias específicas relacionadas con las funciones y niveles de desempeño anteriormente mencionados.

2. Rige para estructuras o partes de estructuras comprendidas en el campo de aplicación de NCh 1198-1 y que se han calculado de acuerdo con dicha norma.(Instituto Nacional de Normalización, 2014)

Dada la proximidad temática de esta normativa, sería necesario incluir exigencias adicionales, basadas en NFPA (2018) y AUSTRALIAN STANDARD®. AS3959. (2009), ambas descritas precedentemente para áreas según riesgo de incendios forestales. Dicha norma no debiese circunscribirse a sólo aspectos de las edificaciones, sino más bien tender a incluir la vegetación, la urbanización, pensando en una protección integral del entorno, así como del perímetro exterior de las edificaciones, resguardando el uso de materiales combustibles y la toxicidad de combustión, sellando herméticamente para evitar el ingreso de pavesas, así como la no adición de estructuras debilitantes o trasmisoras de llamas, la compartimentación y aislamiento de galpones y bodegas que contengan combustibles como leñeras, entre otros, tal como está extensamente descrito en las normas internacionales.

\section{Conclusiones y recomendaciones}

Chile no tiene actualizadas sus normas para atender los incendios de interfaz urbano/ forestal los cuales han ido cambiando y aumentado en magnitud y proporcionalidad de los daños asociados. Los instrumentos de ordenamiento territorial al respecto, presentan limitaciones: están desactualizados, atrasados en su elaboración, o bien, no consideran la planificación preventiva para este tipo de amenazas cada vez más crecientes.

Las normas nacionales, por lo tanto, solo responden a la prevención de incendios que se desencadenan desde las edificaciones hacia el exterior y los entornos y no al revés o su ocurrencia y efectos desde la dirección contraria.

La revisión de normas internacionales recomienda considerar estos aspectos tal como los países desarrollados están actualizando sus instrumentos preventivos desde un nivel macro hasta uno micro, desde las localidades, ciudades, hasta las viviendas, reconociendo que las fronteras o límites de crecimiento de lo urbano, es un acontecimiento constante, cambiante y dinámico. La acción de la comunidad organizada es parte de los atributos resilientes de los sistemas en su condición social.

A nivel comunal, como lo demuestra el caso de estudio, es posible aplicar los aprendizajes internacionales sobre el problema, sumando a ello, protocolos de actuación a esa escala u ordenanzas más específicas diseñadas y comprometidas con la participación de la comunidad. Todo

ACE, 16 (4.6) CC BY-ND 3.0 ES | UPC Barcelona, España | Viviendas ubicadas en áreas de riesgo de incendios 16 forestales de interfaz. Un análisis territorial y normativo desde Chile. DOI: http://dx.doi.org/10.5821/ace.16.46.9523 
ello, en complementariedad con estudios previos de identificación de los grados de la amenaza, vulnerabilidades y condiciones estructurales incidentes.

La planificación urbana da mejores resultados, en relación a los incendios de interfaz, cuando es preventiva y así lo demuestra la revisión de casos internacionales.

Los instrumentos de ordenamiento territorial, son unas de las medidas no estructurales más incidentes en el problema, pero ellos adolecen de una temporalidad negativa, en cuanto, van atrás de este tipo de amenazas y sus impactos. El reconocimiento de tal incidencia podría ser parte de los diseños a incorporar en este tipo de herramientas o medio en cuanto a considerar las áreas de interfaz como un proceso altamente dinámico y estratégico presente en las escalas meso y macro como las analizadas. En cierto modo, dotar estos medios de componentes de resiliencia adaptativa continua y preventiva.

Por ello, junto con lograr que las construcciones, en particular las de madera sean más resistentes al fuego, es necesario considerar acciones efectivas basadas en la experiencia y conocimiento del entorno que les rodea y las áreas edificadas, consecuentemente, no sólo se requiere de regulaciones cuando el incendio se inicia en el interior del edificio, sino también cuando viene desde fuera.

Esta revisión entrega antecedentes que constatan la tendencia en aumento de riesgos de desastres como consecuencia de los cambios en el clima y la necesidad de transformaciones y adaptaciones profundas a las exigencias constructivas. En cuyo caso, la organización, protocolos y compromisos de las empresas constructoras y la innovación de elementos y sistemas constructivos, son clave.

Tales recomendaciones, no obstante, serían insuficientes si los instrumentos de construcción, y fiscalización sobre el uso del suelo y el ordenamiento territorial, no incluyen los riesgos de incendios de interfaz en sus corpus normativos acorde a las condiciones geomorfológicas y territoriales de la división administrativa y de gobernanza que tiene cada lugar o localidad.

Finalmente, es posible afirmar que las consecuencias económicas de la pandemia y sus efectos en la economía pública y privada, serán nuevos factores que, en Chile, incidirán negativamente en el problema investigado y sus múltiples factores incidentales.

\section{Agradecimientos}

El equipo de investigadores agradece a FONDEF de CONICYT, Ilustre Municipalidad de San José de Maipo y CONAF por el apoyo prestado a la ejecución de estas investigaciones.

\section{Autoría}

La primera autora realizó el diseño metodológico, la revisión de la literatura y elaboró el marco teórico, redactando además el capítulo de resultados. El segundo autor elaboró el análisis de comportamiento al fuego para el área de estudio y el tercer autor realizó la revisión y edición final . Así mismo, todos los autores participaron en la documentación, análisis de datos y redacción.

Conflicto de intereses: Los autores declaran que no hay conflicto de intereses.

ACE, 16 (4.6) CC BY-ND 3.0 ES | UPC Barcelona, España | Viviendas ubicadas en áreas de riesgo de incendios 


\section{Bibliografía}

Arteaga, C; Tapia, R. (Editores). (2014). Vulnerabilidades y desastres socionaturales. Experiencias recientes en Chile. Editorial Universitaria. Estudios. Santiago, Chile. Recuperado de http://repositorio.uchile.cl/handle/2250/136617

AUSTRALIAN STANDARD®. AS3959. (2009). Construction of buildings in bushfire- prone areas. 107p. Recuperado de https://publicdocs.scc.qld.gov.au

Balbontín, S. (2020). La experiencia sensible del paisaje sonoro frente a la catástrofe natural: el caso del tsunami del $27 \mathrm{f}$ en Caleta Tumbes, Talcahuano, Chile. ACE: Architecture, City and Environment, 14(42), 7007. DOI: http://dx.doi.org/10.5821/ace.14.42.7007

Barrientos, M. (2016). La arquitectura de los terremotos en Chile (1929-1972). (Tesis Doctor en Arquitectura y Estudios Urbanos). Recuperado de https://repositorio.uc.cl/handle/11534/21371

Barahona Menares, L. F. (2020). Edificios resistentes a los terremotos en Chile. (Tesis de Técnico Universitario). Recuperado de https://hdl.handle.net/11673/48858

BCN. (2017). Australia y la planificación de sus ciudades para evitar la propagación de incendios forestales. Recuperado de https://www.bcn.cl/observatorio/asiapacifico/noticias/australiaplanificacion-ciudades-incendios-forestales

Bowman, D., Moreira, A., Kolden, C., Chávez, R., Muñoz, A., salinas, F., González, A., Rocco, R., de la Barrera, F., Williamson, G., Borchers, N., cifuentes, L., Abatzoglou, J., Johnston, F. (2018). Humanenvironmental drivers and impacts of the globally extreme 2017 Chilean fres. Ambio. DOI: https://doi.org/10.1007/s13280-018-1084-1.

Castillo, M; Molina, J-R; Rodríguez y Silva, F; julio, G. (2013). Fire vulnerability model in Mediterranean ecosystems of South America. Ecological Informatics. 13, 106-113. DOI: http://dx.doi.org/10.1016/j.ecoinf.2012.06.004

Castillo, M.; Molina, J-R.; Rodríguez y Silva, F.; García-Chevesich, P.; Garfias, R.A System to evaluate fire impacts from simulated fire behavior in Mediterranean areas of Central Chile. Science of the Total Environment. DOI: http://dx.doi.org/10.1016/j.scitotenv.2016.11.139.

Castillo Soto, M.; Garay Moena, R.; Tapia Zarricueta, R.; Garfias, R. y Orell Arenas, M. (2020). Metodología de evaluación de infraestructuras críticas en zonas de riesgo de incendios forestales. Recuperado de http://repositorio.uchile.cl/handle/2250/173421

Centro UC de Innovación en Madera (CIM UC). (2019). Guía de Uso de Fichas Técnicas. Recuperado de https://www.disenamadera.cl/templates/plantillaresponsiva/doc/guia-de-uso-de-fichas-tecnicas.pdf

Chas-Amil M.; Toruza J. y García-Martínez E. 2013. Forest fires in the wildland-urban interface: A spatial analysis of forest fragmentation and human impacts. Applied Geography. 43, 127-137. DOI: https://doi.org/10.1016/j.apgeog.2013.06.010

C.F.A (2012). Planning for Bushfire Victoria-Guidelines for Meeting Victoria's Bushfire Planning Requirements. Recuperado de https://www.towong.vic.gov.au/planning-rules-payments/planningbuilding/planning/images/planning-for-bushfire.pdf

CONAF (2020). Índice de probabilidad de Ignición. Recuperado de https://www.conaf.cl/incendiosforestales/combate-de-incendios-forestales/indice-de-probabilidad-de-ignicion/ 
CONAF (2015). ¿Cómo preparo mi casa y entorno frente a los incendios forestales?, Manual de prevención de incendios forestales. Documento de trabajo N601. 123pp.

División Técnica de Estudio y Fomento Habitacional (DITEC, MINVU). (2019). Fomento al Desarrollo Normativo y de Proyectos de Alto estándar Rotulado de la Madera. Departamento de Tecnologías de la Construcción. Presentado en Seminario Rotulado de la madera: experiencias y capacidades de la industria INN. 13 de junio.

Dombeck, M.P.; Williams, J.E. y Wood, C.A. (2004). Política para fuegos no controlados y tierras públicas: integración de la comprensión científica con las preocupaciones sociales en todos los paisajes. Conservation Biology, 18: 883-889. DOI: https://doi.org/10.1111/j.1523-1739.2004.00491.x

Fernández Aragón, I. et al. (2021). Análisis de la desigualdad urbana. Propuesta de un Índice Sintético de Vulnerabilidad Urbana Integral (ISVUI) en Bilbao. ACE: Architecture, City and Environment, 15(45), 9520. DOI: http://dx.doi.org/10.5821/ace.15.45.9520

Flannigan, M.; Cantin, A.S.; De Groot, W.J. (2012). Global wildland fire season severity in the 21st century. Forest Ecology and Management. 294(15), 54-61. DOI: https://doi.org/10.1016/j.forec0.2012.10.022

Fisher, R. E. (2013). Taking a normative approach to organizational culture change on critical infrastructure protection. Benedictine University.

Galilea Ocón, S. (2019). La tormenta de fuego y la Nueva Santa Olga. Recuperado de http://repositorio.uchile.cl/handle/2250/168038

Garay R.; Contreras Y.; Díaz, J.; Herrera R. y Tapia R. (2020). Policy Brief "Propuestas para repensar las viviendas y el habitar Chile", SERIE DOMESTICAR LA CIUDAD No. 01 / 2020. Editorial Universidad de Chile. 13 p. Recuperado de https://www.uchile.cl/publicaciones/169446/policy-brief-n3

Garay, R.; Herrera, R.; Mejías, C. (2019a). Project shelter, Part 2: Structural Verification. Proyecto Vivienda de Emergencia, Parte 2, Verificación Mecánica. Revista de la Construcción 1479. DOI: https://doi.org/10.7764/RDLC.18.1.68:86

Garay, R. y Pino, N. (2019b). Acoustic behavior in three types of housing: Brick Social Housing, Structural Insulated Panel (SIP) Emergency Housing and Mediagua Emergency Housing. Proyecto Vivienda de Emergencia, Parte 3, Comportamiento acústico. Revista de la Construcción 1425. DOI: https://doi.org/10.7764/RDLC.18.1.96:110

Garay R; Aldunce, P; Castillo M; Tapia R; Herrera, R; Ejsmentewicz D; Sepúlveda S. y Vargas G. (2019c). Planificación territorial en zonas de alto riesgo de desastres, soluciones transformadoras y sus consecuencias en la habitabilidad humana. Congreso Internacional Transformations 2019. Santiago, chile. 16 al 18 de octubre.

Garay, R.; Tapia, R.; Castillo, M. y Vergara, J. (2019d). Territorio, viviendas y áreas de incendios forestales de interfaz: localidades periurbanas en torno al Gran Santiago, Chile. A: Seminario Internacional de Investigación en Urbanismo. "XI Seminario Internacional de Investigación en Urbanismo, BarcelonaSantiago de Chile, junio 2019". Barcelona: DUOT. Recuperado de http://hdl.handle.net/2117/171675

Garay R.; Pfenniger F.; Tapia R.; Castillo M. y González M. (2019e). Safe housing, normative changes that transform living. Recuperado de http://www.clem2019.uy/admin/files/clem2019/Garay et al.pdf

Garay, R. M.; Tapia, R.; Castillo, M.; Fernández, O. y Vergara, J. (2018). Habitabilidad de edificaciones y ranking de discriminación basado en seguridad y sustentabilidad frente a eventuales desastres. Estudio de caso: Viviendas de madera. REDER, 2(2), 28-45. Recuperado de http://www.revistareder.com/ojs/index.php/reder/article/view/16

ACE, 16 (4.6) CC BY-ND 3.0 ES | UPC Barcelona, España | Viviendas ubicadas en áreas de riesgo de incendios

forestales de interfaz. Un análisis territorial y normativo desde Chile. DOI: http://dx.doi.org/10.5821/ace.16.46.9523 
Garay, R.; Castillo M. y Fernández O. (2016). La problemática de la protección contra el fuego en la construcción de viviendas y su relación con otros criterios técnicos. V Congreso Red Iberoamericana de protección de la madera. RIPMA. Colonia, Uruguay.

Generalitat Valenciana. 2014. Guía metodológica de actuaciones de prevención, defensa y autoprotección en la interfaz urbano forestal. Recuperado de https://agroambient.gva.es/documents/162905929/162908876/31f

GMV. Resultados del proyecto Firesmart para la prevención de incendios (2012). Recuperado de https://www.gmv.com/es/Empresa/Comunicacion/NotasDePrensa/2012/NP 016 Firesmart.html

González González, Luis Eduardo. (2017). Gestión Territorial post 27-F en Chile: Implicancias sobre el Hábitat Residencial. Bitácora Urbano Territorial, 27(2), 109-116. DOI: https://doi.org/10.15446/bitacora.v27n2.48322

González, M., Vásquez, L. y Hernández, G. (2016). Guía práctica para la construcción de viviendas de madera con sistema plataforma, (185), $126 . \quad$ Recuperado de http://biblioteca.infor.cl/DataFiles/26793.pdf

Groot, M.; Flannigan y Brian J. (2012). El Cambio Climático y los Incendios Forestales. Memorias del Cuarto Simposio Internacional Sobre Políticas, Planificación y Economía de los Incendios Forestales: Cambio Climático e Incendios Forestales. México.

Halgamuge, M. N., Daminda, E., \& Nirmalathas, A. (2020). Best optimizer selection for predicting bushfire occurrences using deep learning. Natural Hazards, 103, 845-860.

Herrero-Corral G.; Jappiot M; Buillon C. \& Long-Fournel M. (2012). Application of a geographical assesment method for the characterization of wildland-urban interfaces in the context of wildfire prevention: A case study in western Madrid. Applied Geography. 35(1-2), 60-70. DOI: https://doi.org/10.1016/j.apgeog.2012.05.005

Ilustre Municipalidad de San José de Maipo (2010a). PLADECO (Plan de Desarrollo Comunal) San José de Maipo año 2010- 2014. Tomo I. Desarrollado por PAC Consultores. 26 enero 2016. Recuperado de http://www.sanjosedemaipo.cl/documents/4/TOMO I PLADECO San Jose 1.pdf

Ilustre Municipalidad de San José de Maipo (2010b). PLADECO (Plan de Desarrollo Comunal) San José de Maipo año 2010- 2014. Tomo II. Desarrollado por PAC Consultores. 26 enero 2016. Recuperado de https://www.sanjosedemaipo.cl/documents/5/TOMO II PLADECO San Jose 1.pdf

Ilustre Municipalidad de San José de Maipo (2016a). Acto administrativo de inicio EAE Plan Regulador de San José de Maipo. abril $2016 . \quad$ Recuperado de https://drive.google.com/file/d/OBwTVQeTBuTb4aXcwWjdDYVBPMmc/edit

Ilustre Municipalidad de San José de Maipo (2016b). Estudio "Actualización y Adecuación del Plan Regulador Comunal de San José de Maipo" Propuesta de ordenanza local, Etapa A.F.E. Ordenanza

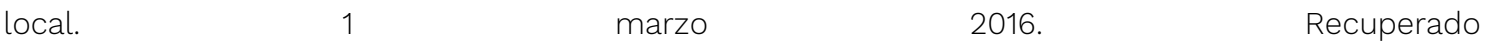
https://www.sanjosedemaipo.cl/documents/13/Propuesta ORDENANZA PRC-SJM.pdf

Instituto Nacional de Normalización (CHILE) (1993). Prevención de incendios en edificios Características pirógenas de materiales de construcción NCh1913.1988. Santiago, Chile. 15 p.

Instituto Nacional de Normalización (INN). (1997). Norma Chilena Oficial NCh 935/1.Of97. Prevención de incendio en edificios-Ensayo de resistencia al fuego - Parte 1: Elementos de construcción en general. Santiago, Chile: Autor.

ACE, 16 (4.6) CC BY-ND 3.0 ES | UPC Barcelona, España | Viviendas ubicadas en áreas de riesgo de incendios 20 forestales de interfaz. Un análisis territorial y normativo desde Chile. DOI: http://dx.doi.org/10.5821/ace.16.46.9523 
Instituto Nacional de Normalización (INN). (2014). Norma Chilena Oficial NCh 1198:2014. Madera Construcciones en madera-Cálculo. Santiago, Chile: Autor.

Instituto Nacional de Normalización, INN (2019). Herramientas normativas para el mejoramiento de los estándares relacionados a la madera para el uso en edificaciones en Chile.

Instituto Nacional de Estadísticas, INE (2018; 2019). https://www.ine.cl/

Khan, S.; Crozier, M.J. y Kennedy, D. (2012). Influencias de las características del lugar sobre los peligros, la percepción y la respuesta: un estudio de caso del paisaje de peligro de la Región de Wellington, Nueva Zelanda. Nat Hazards, 62, 501-529. DOI: https://doi.org/10.1007/s11069-012-0091-y

Longstaff, P. H.; Armstrong, N. J.; Perrin, K.; Parker, W.; M., \& Hidek, M. A. (2010). Building resilient communities: A preliminary framework for assessment. Homeland security affairs, 6(3), 1-23.

López, N. 2009. Plan de protección contra incendios forestales de interfaz urbano-forestal en la Comuna de Tomé, provincia de Concepción (Chile). (Trabajo profesional de fin de carrera. Escuela Técnica Superior de Ingenieros Agrónomos y de Montes). Departamento de Ingeniería Forestal. Universidad de Córdoba. España.

Macari, R. (2015). Criterios que determinan los requerimientos de resistencia al fuego de elementos estructurales (Tesis de Pregrado). Santiago de Chile: Universidad de Chile. 90 p.

Micheletti, Stefano; Pancani, Dante y Pisani, Elena. (2020). Análisis comparativo de la lógica técnicopolítica de reconstrucción: terremoto e incendios forestales en el Maule, Chile. Revista INVI, 35(98), 155-183. DOI: https://dx.doi.org/10.4067/S0718-83582020000100155

Ministerio de Vivienda y Urbanismo, MINVU. (2009). Ordenanza General de Urbanismo y Construcciones, OGUC, Titulo 4: De la Arquitectura. Capítulo 3: De las Condiciones de Seguridad Contra Incendio. Santiago de Chile: MINVU.

Ministerio de Vivienda y Urbanismo, MINVU. (2014a). Listado oficial de comportamiento al fuego de elementos y componentes de la construcción. Santiago de Chile: MINVU.

Ministerio de Vivienda y Urbanismo (2014b). Política Nacional de Desarrollo Urbano. Hacia una nueva politica urbana para Chile. Santiago, Chile. Recuperado de: https://cndu.gob.cl/wpcontent/uploads/2014/10/L4-Politica-Nacional-Urbana.pdf

Ministerio de Vivienda y Urbanismo. (2016). Estándares de construcción sustentable para viviendas de Chile Tomo l: Salud y bienestar. División Técnica. Recuperado de http://csustentable.minvu.gob.cl/wp-content/uploads/2016/11/ECSV 1.pdf

Ministerio de Vivienda y Urbanismo. (2018). Estándares de Construcción Sustentable para Viviendas de Chile-Tomo II Energía. Santiago, Chile: Recuperado de https://csustentable.minvu.gob.cl/wpcontent/uploads/2018/09-ENERGIA.pdf

Ministerio de Vivienda y Urbanismo. (2018). Requisitos de Rotulado de la madera aserrada para construcción. Recuperado de https://csustentable.minvu.gob.cl/wp-c/upl/2018/04/Rotulado-MaderaProveedores.pdf

Ministerio de Vivienda y Urbanismo. (2019). Manual de aplicación de la Certificación vivienda sustentable. Recuperado de https://csustentable.minvu.gob.cl/wp-content/uploads/2019/11/ManualCertificaci\%C3\%B3n-Vivienda-Sustentable-Nov2019.pdf

National Fire Protection Association NFPA 1144. (2018). Standard for Reducing Structure Ignition Hazards from Wildland Fire. Quincy, Massachusetts: IHS.38 p.

ACE, 16 (46) CC BY-ND 3.0 ES | UPC Barcelona, España | Viviendas ubicadas en áreas de riesgo de incendios 21 forestales de interfaz. Un análisis territorial y normativo desde Chile. DOI: http://dx.doi.org/10.5821/ace.16.46.9523 
National Fire Protection Association NFPA 5000®. (2018) Building Construction and Safety Code® 2018 Edition. Quincy, Massachusetts: IHS.721 p.

National Fire Protection Association NFPA 1141. (2017). Standard for Fire Protection Infrastructure for Land Development in Wildland, Rural, and Suburban Areas. Quincy, Massachusetts: IHS. 9 p.

National Fire Protection Association NFPA 703. (2000). Standard for Fire Retardant Impregnated Wood and Fire-Retardant Coatings for Building Materials. Quincy, Massachusetts: IHS. 9 p.

National Fire Protection Association NFPA 101 (2000). Código de Seguridad Humana. Quincy, Massachusetts: IHS. 519 p.

NFPAJL. (2017). Construir, quemar, repetir. Recuperado de http://www.nfpajla.org/archivos/edicionimpresa/incendios-forestales/1322-construir-quemar-repetir

NFPAJL. (2019a). Interfaz Urbano/Forestal. Recuperado de http://www.nfpajla.org/archivos/exclusivos -online/incendios-forestales/1284-interfaz-urbano-forestal

NFPAJL. (2019b). Conocer el mundo del otro. Recuperado de http://www.nfpajla.org/archivos/exclusi vos-online/incendios-forestales/1231-conocer-el-mundo-del-otro

Oficina Nacional de Emergencia del Ministerio del Interior y Seguridad Pública, ONEMI. Ministerio de Desarrollo Social.; CIGIDEN, Walker V.; R., Wagemann F.; E. CITRID, Garay M.; R., Tapia Z., R. y TECHOCHILE, Domínguez G. M. (2018). Habitabilidad Transitoria en Desastres en Chile. Experiencia en el período 2014-2017. Santiago, Chile. Disponible en http://repositorio.uchile.cl/handle/2250/151726

Olavarría M. (Editor) (2010). ¿Cómo se formulan las políticas públicas en Chile? Tomo I. La modernización de la Gestión Pública. Editorial Universitaria. Santiago, Chile.

Ojeda, L.; Bacigalupe, G. y Pino, A. (2019). Coproducción después de un incendio forestal urbano: reconstrucción posterior a un desastre de un asentamiento informal en Chile. Medio Ambiente y urbanización, 90(1), 205-234.

ONU. (2015). Marco de Sendai para la reducción del riesgo de desastres 2015-2030. New York: Autor. Ordenanza General De Urbanismo y Construcción (OGUC). (2017). Resumen de modificaciones y rectificaciones de la ordenanza general de urbanismo y construcciones. Santiago, Chile. 422p.

Ortega R. (2019). Evaluación del riesgo de incendios forestales para contribuir a su reducción en las comunidades de la diócesis de Talca, Región del Maule. (Memoria para optar al título de Geógrafo) Universidad de Chile, Santiago, Chile.

Pavez Reyes, M. (2013). Una politica de desarrollo urbano sustentable para Chile. Disponible en http://repositorio.uchile.c//handle/2250/145044

Pérez, M. Á. (2016). Seminario Normativa y Resistencia de Materiales -Resistencia al Fuego de Materiales. (C. C. de la C. Corporación de Desarrollo Tecnológico, Ed.). Santiago: Universidad de Chile. Facultad de Arquitectura y Urbanismo, Instituto de la Vivienda. Recuperado de http://www.cdt.cl/download/10909/

Peters M. Iverson L.; Matthews S. \& Prasad A. (2013). Wildfire hazard mapping: exploring site conditions in eastern US wildland-urban interfaces. International Journal of Wildland Fire, $N^{\circ} 22,567-578$. DOI: https://doi.org/10.1071/WF12177

ACE, 16 (46) CC BY-ND 3.0 ES | UPC Barcelona, España | Viviendas ubicadas en áreas de riesgo de incendios 22 forestales de interfaz. Un análisis territorial y normativo desde Chile. DOI: http://dx.doi.org/10.5821/ace.16.46.9523 
Programa de Reducción de Riesgos y Desastres, Unidad de Redes Transdisciplinarias, Vicerrectoría de Investigación y Desarrollo, Universidad De Chile (2020a). Los territorios que habita(re)mos: ¿qué futuro existe para las zonas de sacrificio? DOI: https://doi.org/10.34720/z5ew-4395

Programa de Reducción de Riesgos y Desastres, Unidad de Redes Transdisciplinarias, Vicerrectoría de Investigación y Desarrollo, Universidad De Chile (2020b). Policy Brief "Propuestas para repensar las viviendas y el habitar Chile". Recuperado de https://www.uchile.cl/documentos/policy-briefpropuestas-para-repensar-las-viviendas-y-el-habitar-chile 1694460 3808.pdf

Ramírez Aliaga, P. (2019). Cambios en los usos de suelo, vulnerabilidad del territorio e incendios forestales. El caso de estudio Las Máquinas, Región del Maule, Chile. (Tesis de Master en Estudios Territoriales y de la Población). Recuperado de http://hdl.handle.net/2072/367596

Romero Aravena, H. y Mendonça, M. (2009). Análisis comparativo de los factores naturales y urbanos de las inundaciones ocurridas en las ciudades costeras de Valparaíso y Florianópolis. Recuperado de http://repositorio.uchile.cl/handle/2250/117837

Romero Aloy, M. J. (2019). Riesgo hídrico y planeamiento urbanístico: una confusa complementariedad [en línea] Fecha de consulta: 08-06-21. En: ACE: Architecture, City and Environment, 14 (40): 65-88. DOI: http://dx.doi.org/10.5821/ace.14.40.6471

Rinaldi, A. y Bergamini, K. (2020). Inclusión de aprendizajes en torno a la gestión de riesgos de desastres naturales en instrumentos de planificación territorial (2005-2015). Revista de Geografía Norte Grande. 75: 103-130. DOI: http://dx.doi.org/10.4067/S0718-34022020000100103

Saavedra, J. 2013. "Tipificación y caracterización de interfaces urbano-forestales en la Región Metropolitana. CONAF Región Metropolitana, Departamento de Protección Contra Incendios Forestales, Sección de Prevención de Incendios Forestales. CDC Tarea 13.1.3

SIT.CONAF (2019). Mapa con clasificación de Síntesis de la Región Metropolitana. Recuperado de https://sit.conaf.cl/exp/ficha.php

Stewart S.; Radeloff V.; Hammer R.; Hawbaker T. 2007. Defining the Wildland-Urban Interface. Journal of Forestry. 201-207. DOI: https://doi.org/10.1093/jof/105.4.201 